\title{
iLeger: Uma proposta de Mediação Digital para Períodos Eleitorais
}

\author{
Artur Afonso de Sousa ${ }^{1}$, Luís Borges Gouveia ${ }^{2}$ \\ ajas@di.estv.ipv.pt, lmbg@ufp.edu.pt \\ ${ }^{1}$ Instituto Politécnico de Viseu, Campus Politécnico de Repeses, 3504-510, Viseu, Portugal \\ ${ }_{2}^{2}$ Universidade Fernando Pessoa, Praça 9 de Abril n. ${ }^{\circ}$ 349, 4249-004, Porto, Portugal
}

DOI: $10.4304 /$ risti.9.43-57

\begin{abstract}
Resumo: Neste artigo apresenta-se uma proposta de mediação digital para a participação pública direta em períodos eleitorais. A proposta assenta numa aplicação Web, designada iLeger, baseada nos princípios dos Media Sociais. Pretende-se, com esta proposta, contribuir para reduzir o fosso existente na comunicação entre a comunidade e os candidatos, tornar as campanhas mais abertas e estimular os cidadãos a envolverem-se e a participarem ativamente nos debates eleitorais. Apresentam-se as principais áreas funcionais do iLeger, assim como os resultados de um caso de estudo sobre as Eleições Legislativas Portuguesas de 2011.
\end{abstract}

Palavras-chave: Mediação digital; Eleições; eCampanha; eParticipação; Media Sociais.

\begin{abstract}
This paper presents a proposal for digital mediation for direct public participation during electoral periods. With this proposal, a Web application based on social media principles, it is intended to narrow the communication gap between voters and candidates, make campaigns more open and encourage citizens to become involved and participate in electoral debates. This paper also presents the main features of the proposed Web application and includes results from a case study about the Portuguese Parliamentary Elections held in 2011.
\end{abstract}

Keywords: Digital Mediation; Elections; eCampaigning; eParticipation; Social Media.

\section{Introdução}

A Internet é hoje uma ferramenta que molda a nossa vida em muitos aspetos. Para alguns é uma fonte inesgotável de informação e, para outros é um meio para gerir contas bancárias, fazer compras e utilizar os serviços públicos. Grande parte das 
atividades da vida real tem já uma equivalente em linha. Seguindo essa tendência, também no campo da participação pública se tem verificado uma integração crescente das Tecnologias da Informação e Comunicação e da Internet, levando ao conceito de participação eletrónica - eParticipação (Stanford \& Rose, 2007).

A utilização da Internet tem vindo a tornar-se relativamente mais interativa e orientada para o utilizador. A Web 2.0 e, mais recentemente o surgimento dos Media Sociais, não só criaram novas possibilidades para a comunicação, mas também novas formas de comportamento e envolvimento social e político (Kes-Erkul \& Erdem-Erkul, 2009). Hoje, os sites de redes sociais como o Facebook, YouTube, Twitter, LinkedIn, Wikipedia e Flickr têm milhões de utilizadores ativos. Com os exemplos de mobilização de massas, como a Primavera Árabe e os movimentos de protesto contra a crise económica global, como o Occupy Wall Street (http://occupywallst.org/) e o We Are the 99 Percent (http://wearetheg9percent.tumblr.com/), é seguro afirmar que os Media Sociais estão a transformar a sociedade e o jogo da política. Na revisão da literatura sobre Media Sociais e participação, Effing e os seus colegas alegam que o uso da Internet pelos cidadãos é cada vez mais social e participativo (Effing, Hillegersberg \& Huibers, 2011). Eles ainda argumentam que um fator-chave da Web 2.0 e dos Media Sociais é a participação.

O acréscimo de interatividade torna a utilização da Internet num ambiente importante de comunicação em disputas eleitorais e acaba por diferenciar as campanhas online das campanhas empreendidas nos Media tradicionais. De acordo com (Bimber \& Davis, 2003), a real contribuição democrática das campanhas em linha estaria na apropriação do potencial interativo da Internet para tirar os eleitores da função de meros espetadores.

No entanto, considerando, em campanhas eleitorais, ferramentas como blogues, sites de campanha dos partidos políticos, $e$-mail, boletins informativos, ou abordagens mais tradicionais que cobrem as transmissões de TV, debates, SMS (Short Message Service), contactos porta-a-porta ou discursos públicos, elas estão mais concentradas na comunicação unidirecional, como ilustra a Figura 1, e não suportam um eficiente processo de comunicação escalável baseado nos objetivos e necessidades de todas as partes interessadas.

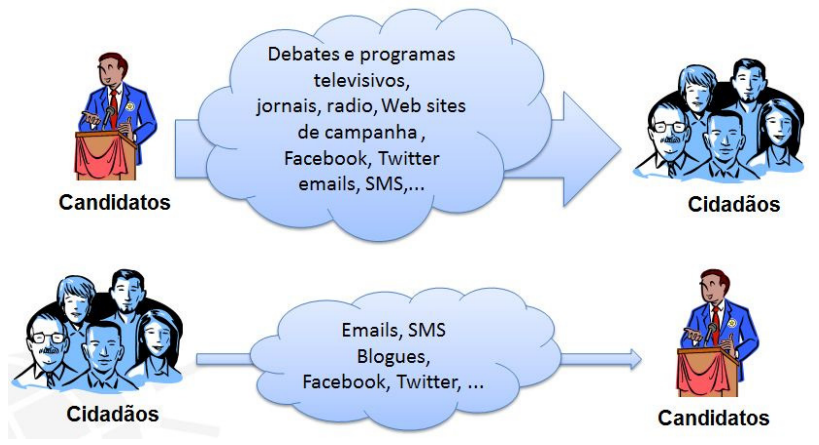

Figura 1 - Comunicação unidirecional entre candidatos e cidadãos 
Se considerarmos a perspetiva do cidadão e o processo de compilação de informação que precede a decisão de voto, temos duas grandes abordagens. A primeira, que pode ser denominada passiva, consiste em assistir a notícias, debates e discursos dos candidatos na televisão ou na rádio, assim como às análises dos comentadores políticos. Na segunda, a ativa, o cidadão consulta o programa eleitoral dos diferentes candidatos, tipicamente nos correspondentes sítios Web, ou eventualmente consulta outros sítios Web que agregam esta informação e providenciam uma comparação entre as posições dos diferentes candidatos sobre vários assuntos chave.

Depois de observar o tipo de comunicação política e de cobertura das campanhas eleitorais operado pelos órgãos de comunicação social tradicionais, surgiu uma pergunta de investigação preliminar importante: como estimular os cidadãos a envolverem-se e a participar ativamente nos debates eleitorais, através de mediação digital?

Neste contexto, acredita-se que pode ser útil e desejável ter uma solução que agregue num único local, neutro e regulado, os principais intervenientes num processo eleitoral e que possibilite uma comunicação multidirecional entre eles, como ilustrado na Figura 2. Isso permitiria que, por um lado, os cidadãos se esclarecessem acerca das questões e problemas mais importantes da sociedade e, por outro lado, que os candidatos tomassem conhecimento das principais ideias e problemas da comunidade sobre as diferentes áreas da governação (educação, saúde, economia, entre outras).

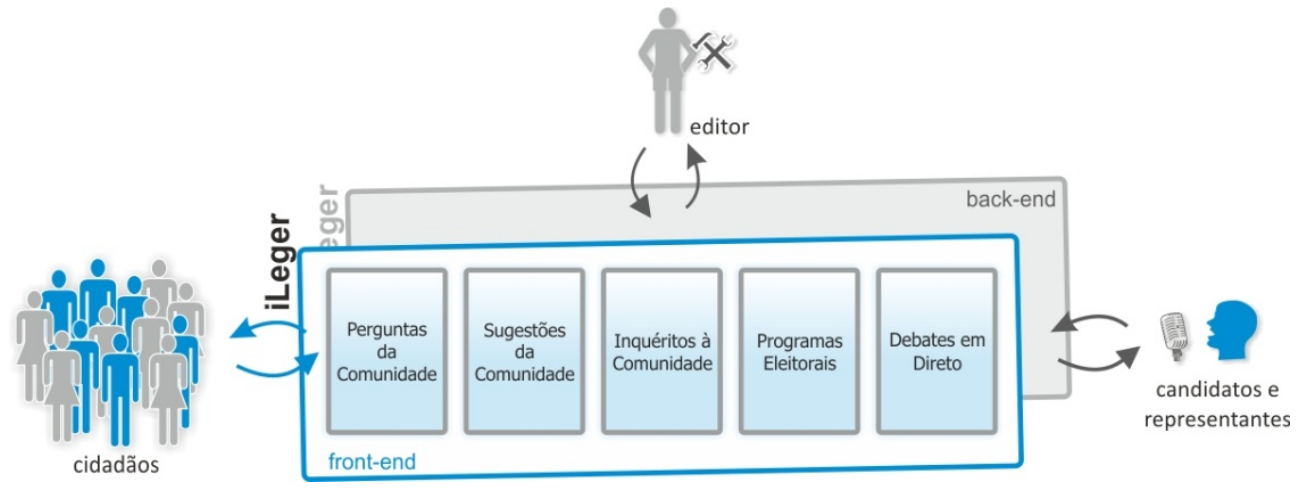

Figura 2 - Comunicação multidirecional entre cidadãos e candidatos

Assim, propõe-se uma aplicação Web, designada iLeger, especificamente concebida para reunir, durante o período eleitoral, os cidadãos e os candidatos a uma eleição num espaço deliberativo compartilhado. A interação e a colaboração são suportadas através de perguntas, respostas, sugestões, comentários, votações e debates em direto. Com esta aplicação pretende-se contribuir para colmatar a lacuna de comunicação identificada entre estes dois principais intervenientes, para tornar as campanhas mais abertas a discussões com o eleitorado e para converter o eleitor - que antes exercia a função de consumidor de informação - num agente com capacidade de intervir e de produzir informação.

A aplicação iLeger está integrada no projeto Liberopinion (http://www.liberopinion.com) que visa criar uma plataforma tecnológica na área dos 
Media Sociais e da eParticipação, com ênfase na interação entre os utilizadores. Atualmente, a plataforma Liberopinion consiste em duas aplicações, a descrita neste artigo, iLeger e o Governómetro (Afonso de Sousa \& Borges Gouveia, 2011), que visa monitorizar o desempenho da atividade governativa. Em síntese, o Governómetro é uma aplicação Web baseada nos princípios da eParticipação, especificamente projetada para monitorizar e discutir, de forma objetiva e independente, a atividade do governo e as novas leis a nível nacional, regional ou local. Numa primeira fase, o Governómetro foca três aspetos: a evolução dos indicadores de conjuntura, os objetivos do governo e as medidas de governação.

A aplicação iLeger foi recentemente testada na Eleição do Bastonário da Ordem dos Médicos de Portugal de 2010 (http://om.ileger.sapo.pt) e foi usada em parceria com o maior portal Web português (SAPO - http://www.sapo.pt), propriedade da Portugal Telecom, nas Eleições Presidenciais Portuguesas de 2011 (http://presidenciais.ileger.sapo.pt) e nas Eleições Legislativas Portuguesas de 2011 (http://ileger.noticias.sapo.pt/legislativas/2011/).

Este artigo está estruturado do seguinte modo: Na secção 2 apresentam-se algumas iniciativas de participação em linha em períodos eleitorais. Na secção 3 descrevem-se as principais áreas funcionais da aplicação iLeger. Na secção 4 são apresentados os resultados de um caso de estudo sobre as Eleições Legislativas Portuguesas de 2011. Finalmente, na secção 5 apresentam-se os comentários finais e abordam-se alguns tópicos para futura investigação.

\section{Mediação digital e eleições}

Têm sido levadas a cabo várias iniciativas em linha para ajudar os cidadãos a esclarecer as questões e as propostas eleitorais por parte dos diferentes candidatos. Uma abordagem conhecida apresenta um questionário aos cidadãos sobre vários assuntos, faz uma comparação estatística com as posições dos candidatos e obtém o candidato que melhor corresponde às respostas do utilizador (Smartvote, 2005). Todavia, isso não permite que o cidadão comunique e envie perguntas aos candidatos. Ademais, as perguntas formuladas são baseadas no programa eleitoral, tal como definido por cada candidato e não fornecem qualquer base para a interação. Também existem outros sites que comparam as propostas dos candidatos em vários tópicos (CNN Election Center, 2010).

Uma outra abordagem procura retificar a lacuna na comunicação entre os cidadãos e os políticos (Abgeordneten, 2010). Nessa iniciativa, é exibida a lista de representantes políticos, bem como dos candidatos às eleições, e os cidadãos podem enviar perguntas para os candidatos responderem. Porém, o site está desenhado em torno de cada representante político e não parece oferecer nem uma solução escalável quando o número de perguntas aumenta, nem uma comparação direta (lado a lado) das respostas dos candidatos para uma mesma pergunta, e nem a possibilidade de debater em torno da questão e das respetivas respostas.

Em (Aggio, Marques \& Sampaio, 2011) descreve-se uma iniciativa de participação mantida pelo candidato José Serra às Eleições Presidenciais Brasileiras de 2010. Resumidamente, ao longo da primeira fase das eleições a campanha de José Serra 
lançou uma plataforma Web de comunicação cujo objetivo era a construção de um plano de governação colaborativo, apto a agregar contribuições de cidadãos, especialistas e demais interessados em questões políticas relevantes para o Brasil. Para o efeito, foram criados fóruns temáticos classificados de acordo com a região do país ou com a natureza da questão abordada. Em (Talbot, 2008; Greengard, 2009) é analisada, a partir de uma perspetiva de eParticipação, a bem-sucedida campanha eleitoral de Barack Obama durante as Eleições Presidenciais de 2008. Todavia, essas abordagens servem essencialmente para envolver os cidadãos em torno de uma candidatura. Isto é, não juntam num único espaço os vários candidatos e os cidadãos para comunicarem e partilharem ideias e opiniões.

O espaço U.S. Politics no Facebook (http://www.facebook.com/uspolitics) destaca o uso desta rede social por políticos. Uma iniciativa interessante, levada a cabo por uma parceria entre o Facebook e a estação de televisão NBC, transmitiu ao vivo, em http://www.facebook.com/uspolitics?sk=app_201387976576727, o debate entre os candidatos presidenciais do Partido Republicano (Grand Old Party - GOP) realizado em 8 de Janeiro de 2012. Nesse espaço os cidadãos foram previamente convidados a submeter questões para os candidatos. Algumas dessas perguntas foram depois usadas durante o debate, juntamente com as perguntas do moderador, o jornalista David Gregory, e com mais algumas perguntas colocadas por cidadãos enquanto decorria o debate. Há, todavia, a questão sobre o modo de seleção das perguntas para o debate. Apesar de possuir uma premissa participativa, a iniciativa não é clara sobre as regras de seleção, não havendo qualquer referência ao modo de escolha das perguntas. Uma outra limitação da iniciativa diz respeito à organização da informação. Não existia nenhuma estrutura temática para a submissão de perguntas. Por outro lado, também não existiam áreas específicas para a submissão de sugestões, nem para realizar inquéritos aos cidadãos.

\section{Estrutura funcional da aplicação iLeger}

A plataforma iLeger foi projetada e desenvolvida de raiz para atender às necessidades e aos objetivos dos principais intervenientes no processo eleitoral, nomeadamente os cidadãos e os candidatos. Como ilustrado na Figura 3, a aplicação permite ao editor criar e gerir cinco tipos de iniciativas de participação em linha: perguntas dos cidadãos e respetivas respostas dos candidatos, sugestões e ideias da comunidade, inquéritos aos cidadãos, o programa eleitoral dos candidatos e, finalmente, debates em direto. A gestão da plataforma, dos utilizadores e dos eventos de participação, incluindo a sua moderação, é da responsabilidade do editor. 


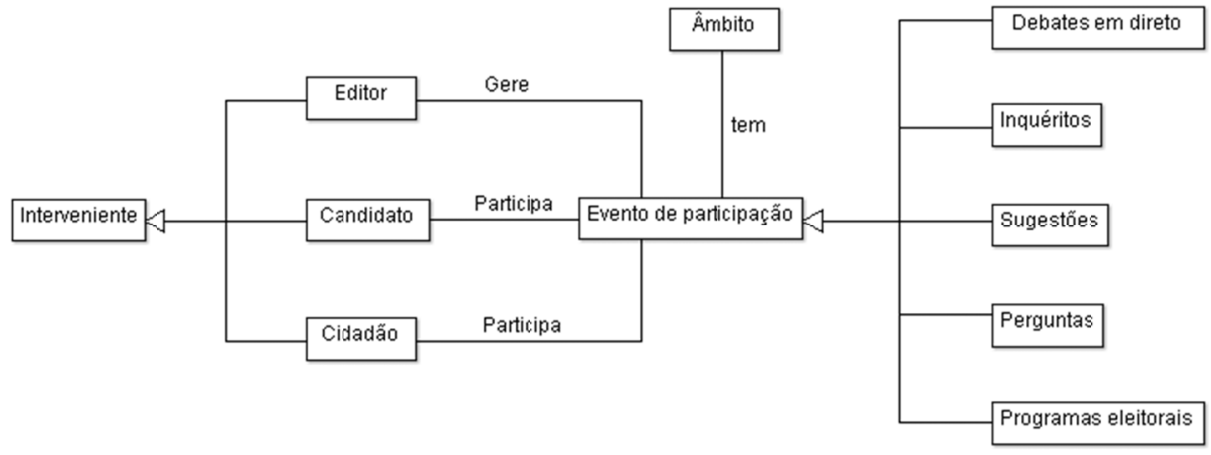

Figura 3 - Diagrama de classes UML simplificado da aplicação iLeger

Convém referir que, nas Eleições Legislativas Portuguesas de 2011, para poder usufruir das principais funcionalidades, tais como submeter perguntas, sugestões, comentários e votar, cada utilizador tinha que estar previamente registado na plataforma e tinha que efetuar o login. Por outro lado, caso não efetuasse o login, o utilizador apenas podia consultar os conteúdos da aplicação. No entanto, é possível configurar o iLeger para diferentes definições, de modo a permitir a interação por utilizadores não registados. Por exemplo, há um cenário em que utilizadores não registados podem votar, mas não podem introduzir conteúdos, e outro em que é permitida a votação e a introdução de conteúdos. Na última configuração, a única limitação para os utilizadores não registados é a falta de notificações por e-mail e dos recursos adicionais característicos das redes sociais, tais como seguir utilizador e acesso ao perfil público.

Todas as intervenções dos cidadãos foram alvo de moderação, de acordo com as regras de utilização da plataforma. Note-se que quando se registavam na plataforma, os utilizadores tinham que aceitar os termos de utilização. Por outro lado, as intervenções dos candidatos não foram moderadas. De modo a incentivar a participação, foi permitido aos cidadãos requerer o anonimato em todas as intervenções escritas submetidas na plataforma. Não obstante, a plataforma está desenhada para suportar diferentes configurações para a moderação. Por exemplo, é possível publicar diretamente todo o conteúdo, ou seja, desabilitar a moderação, ou moderar apenas as entradas denunciadas pelos utilizadores da plataforma.

Acredita-se que as redes sociais em linha serão cada vez mais importantes para as comunidades. Assim, considera-se muito importante munir a plataforma iLeger com recursos característicos das redes sociais. Por exemplo, um utilizador registado pode seguir outros utilizadores registados na plataforma. Todos os utilizadores registados possuem uma área de perfil onde podem colocar informação pessoal, nomeadamente dados de contacto, links para as suas páginas nas redes sociais e de blogues. Na área de perfil público de cada utilizador é também apresentada a sua atividade (as suas perguntas, sugestões e comentários) recente no iLeger, bem como a sua rede social.

A integração da plataforma com as redes sociais também é de suma importância. Por esse motivo, e como um passo inicial nessa direção, os utilizadores podem partilhar no Facebook e publicar diretamente no Twitter as perguntas e sugestões submetidas no iLeger. Deste modo, providencia-se uma interface mais aberta para promover a 
participação e reforça-se a voz do cidadão, uma vez que se aumenta o alcance e o potencial impacto de participação de cada indivíduo. Note-se que a publicação nas redes sociais não depende da aprovação do moderador.

Atualmente, o iLeger pode também ser configurado em relação ao tipo de interação dos candidatos. Estão previstos dois cenários: com ou sem interação por parte dos candidatos. Com interação, os candidatos têm uma conta de acesso e são responsáveis pela introdução de conteúdos, permitindo a comunicação direta com os outros utilizadores. Na ausência de interação do candidato, o iLeger pode ser usado pelo editor para identificar as principais questões e sugestões dos eleitores, bem como as suas opiniões sobre as questões-chave sobre a eleição. O editor pode também colocar conteúdos sobre as candidaturas para que os cidadãos possam analisar e comentar. A seguir, apresentam-se as principais funcionalidades da aplicação, organizadas por ator.

\subsection{Cidadãos}

Resumidamente, como pode observar na Figura 4, os cidadãos podem submeter perguntas, sugestões e comentários, votar, participar em debates em direto, definir critérios para receber notificações (por exemplo: quando um candidato responde a uma pergunta ou comenta uma sugestão do utilizador, quando outro utilizador responde a um comentário do utilizador, entre outros), seguir ou deixar de seguir outros utilizadores e candidatos, editar o seu perfil público, propor sugestões para melhoria do iLeger.

Os cidadãos podem ainda visualizar um vasto conjunto de informação. Por exemplo, podem consultar e comparar as respostas dos candidatos; consultar, avaliar e comentar os programas eleitorais propostos por cada candidatura; consultar o perfil público dos outros utilizadores e dos candidatos, bem como a rede (seguidores) e a atividade do candidato na plataforma; consultar o arquivo; consultar resultados estatísticos; visualizar os TOPs das perguntas e das sugestões mais populares, etc. 


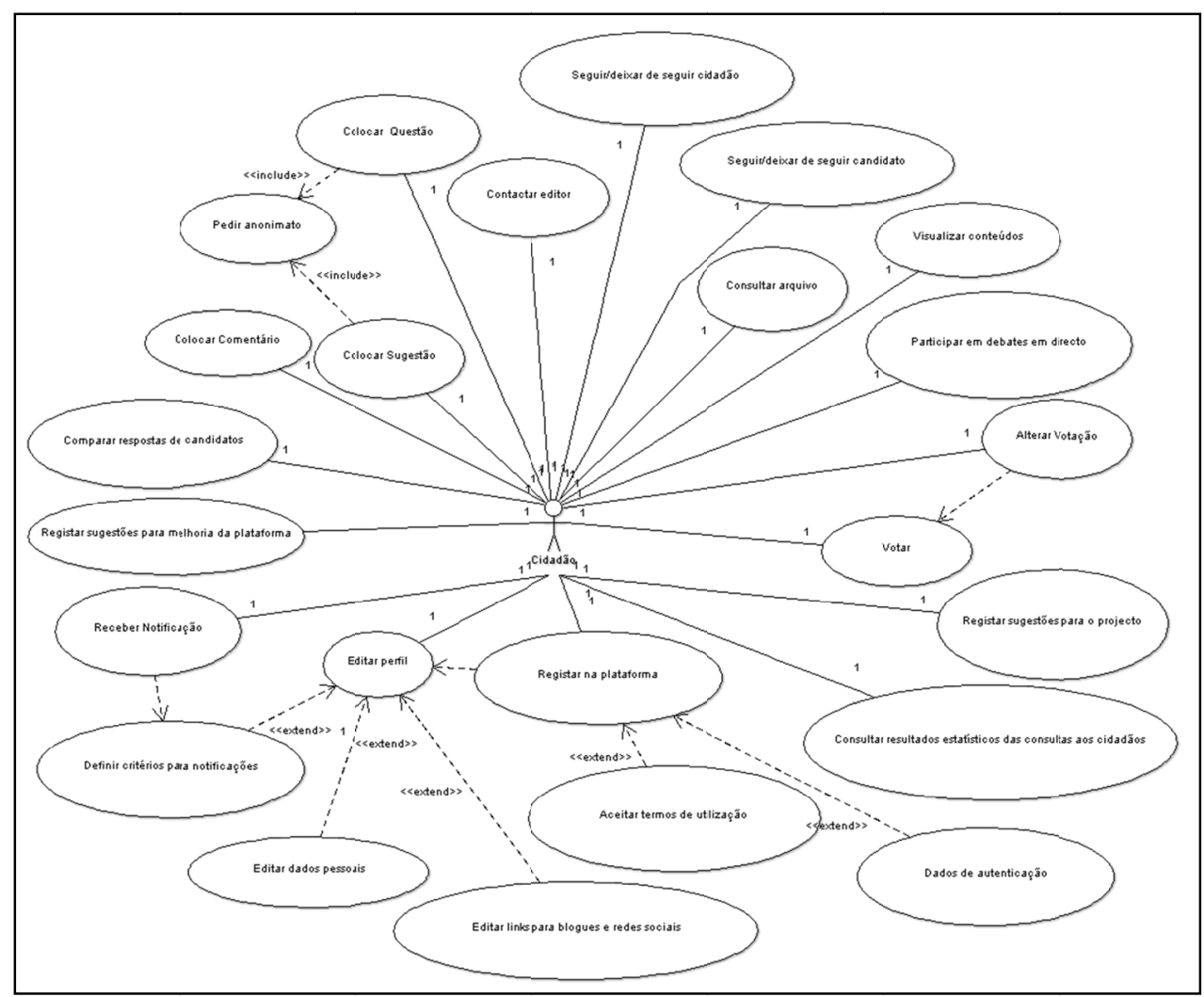

Figura 4 - Diagrama de casos de uso simplificado do ator cidadão

\subsection{Candidatos e representantes}

No caso de o iLeger estar configurado para haver interação direta dos candidatos, como pode observar na Figura 5, os candidatos e os seus representantes podem editar o seu perfil, responder a perguntas colocadas pelos cidadãos, comentar sugestões, marcar perguntas e sugestões para responder e comentar mais tarde, comentar respostas e comentários a sugestões de outros candidatos, participar em debates em direto, consultar dados estatísticos das consultas feitas aos cidadãos, definir critérios para receber notificações (por exemplo: quando outro candidato comenta uma resposta ou um comentário seu, quando outro candidato comenta uma proposta eleitoral sua, entre outros), apresentar o seu programa eleitoral (PE), incorporar sugestões dos cidadãos no PE, comentar os PE dos outros candidatos. 


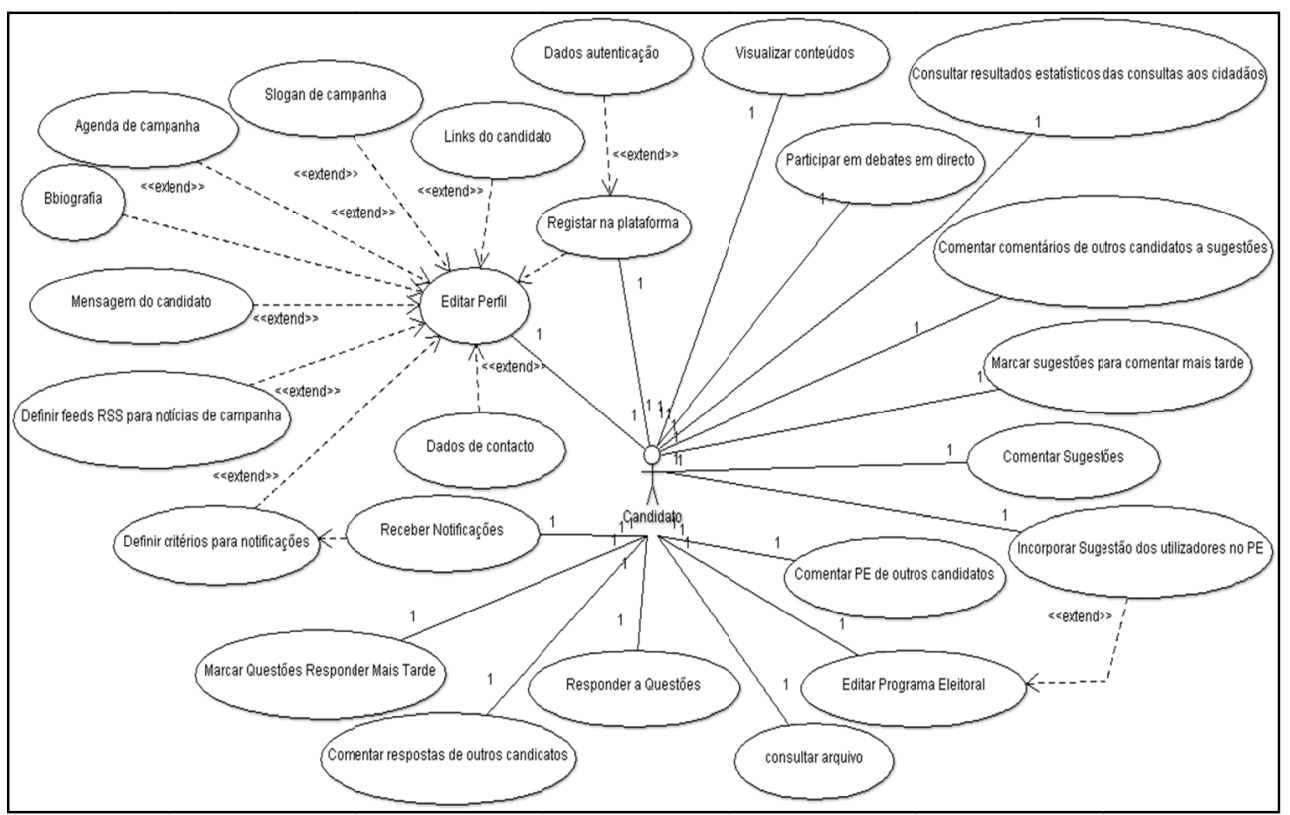

Figura 5 - Diagrama de casos de uso simplificado do ator candidato

O vasto conjunto de informação anteriormente referido para os cidadãos poderem visualizar está também, naturalmente, disponível para os candidatos. Destaca-se ainda a possibilidade de um candidato poder visualizar estatísticas sobre o seu desempenho, nomeadamente as votações às suas respostas e propostas eleitorais, a sua posição no ranking das melhores respostas, o seu nível de atividade, etc.

\subsection{Editor da plataforma}

A administração de utilizadores, a configuração da plataforma e a gestão dos eventos de participação e dos conteúdos editoriais é efetuada a partir de uma secção dedicada, o BackOffice. Como pode observar na Figura 6, o editor da plataforma pode criar eventos de participação para angariação de perguntas e de sugestões, para auscultação da opinião dos cidadãos (inquéritos) e debates em direto. $\mathrm{O}$ editor pode selecionar as iniciativas de participação que quer destacar na respetiva secção (perguntas, sugestões e debates em direto), até a um máximo de quatro em simultâneo. O editor pode ainda definir o modo de moderação de cada evento de participação. Caso defina que o evento é moderado, todos os conteúdos escritos submetidos pelos cidadãos são alvo de moderação. O editor, no papel de moderador, deve fazer a moderação à luz dos termos de utilização do iLeger. O editor pode marcar/selecionar perguntas e sugestões colocadas pelos cidadãos, que considere pertinentes para incluir em TOPs editoriais. 


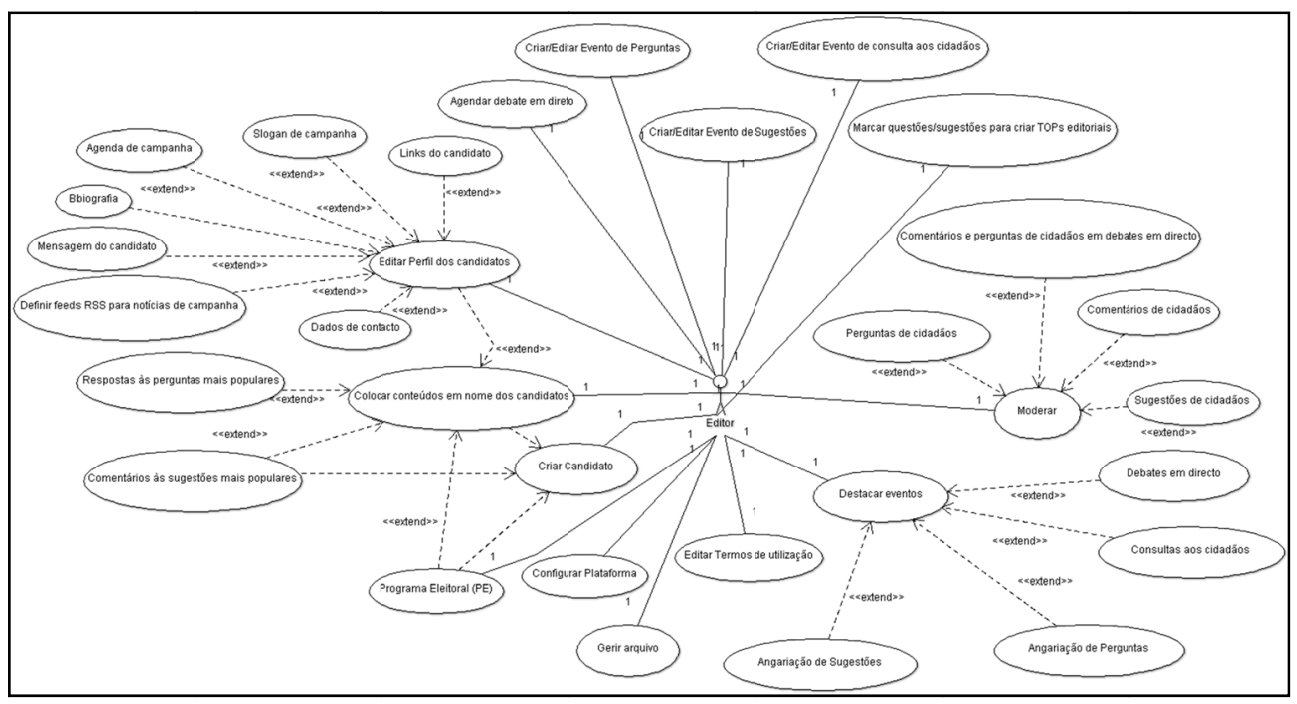

Figura 6 - Diagrama de casos de uso simplificado do ator editor

No caso de o iLeger estar configurado para não haver interação direta dos candidatos, o editor pode colocar informação sobre cada candidato: slogan de campanha, biografia, agenda de campanha, mensagem do candidato, notícias (texto ou através de um feedl RSS), imagens e vídeos de campanha, links para o sítio Web e para as redes sociais da candidatura e o programa eleitoral. Neste cenário, o editor pode ainda usar o iLeger para identificar as melhores questões dos cidadãos eleitores. Depois, pode remetê-las a todos os candidatos para que possam responder. Finalmente, o editor publica no iLeger as respostas dos candidatos para que os cidadãos as possam comparar.

\section{Caso de estudo: As Eleições Legislativas Portuguesas de 2011}

A plataforma iLeger foi usada, em parceria com o maior portal Web de Portugal, o SAPO, propriedade da Portugal Telecom, durante a campanha para as Eleições Legislativas Portuguesas em Junho de 2011. Cobriu as duas últimas semanas antes das eleições, entre 20 de Maio e 3 Junho de 2011.

A versão do iLeger usada foi configurada para que os utilizadores tivessem que se registar para poderem submeter conteúdos (perguntas, sugestões e comentários) e votar. Todos os conteúdos escritos submetidos por cidadãos foram sujeitos a moderação e as várias candidaturas apenas participaram em debates em direto. Notese, contudo, que para participar nos debates em direto não era necessário estar registado no iLeger.

Para o registo dos utilizadores foi usado o mecanismo de Single Sign On (SSO) do nosso parceiro. Desta forma, os utilizadores já registados no SAPO poderiam entrar no iLeger sem necessitarem de efetuar um novo registo. Foram contabilizados 290 utilizadores distintos que efetuaram o login no iLeger, ou seja, que ficaram habilitados para submeter conteúdos escritos e para votar. As estatísticas extraídas do Google 
Analytics mostram que, durante as duas semanas, 21.486 utilizadores únicos visitaram o iLeger (perfazendo um total de 44.777 páginas vistas). Assim, apenas 1,3\% dos visitantes distintos chegaram a efetuar login no iLeger.

Os cidadãos foram convidados a criar um top de 10 perguntas para ser, depois, apresentado simultaneamente às candidaturas durante um debate em direto realizado no dia 31 de Maio de 2011 no Instituto Superior de Ciências Sociais e Políticas (ISCSP). Sucintamente, foram criadas três iniciativas de participação. Cada iniciativa tinha a data limite de 30 de Maio de 2011 para a submissão de perguntas e tinha um tema associado, nomeadamente o crescimento da economia, o estado social e a ajuda externa. Convém referir que, dado o contexto económico e financeiro de Portugal nesse momento, esses foram os temas dominantes da campanha eleitoral. Para tal, os cidadãos inscritos enviaram perguntas e votaram, de acordo com a sua relevância. Nessa fase, foram aceites pelo moderador 107 das 116 perguntas submetidas pelos cidadãos, indicando uma taxa de rejeição de $8 \%$.

O debate do ISCSP foi moderado pela diretora do canal de notícias do portal SAPO e, através de uma parceria entre a estação de televisão SIC Notícias e o portal SAPO, foi difundido em direto no iLeger, via streaming de vídeo. As 10 perguntas mais votadas no iLeger foram as únicas usadas no debate e foram respondidas por cada um dos políticos convidados. A Figura 7 ilustra a difusão do debate na área do iLeger destinada aos debates em direto.

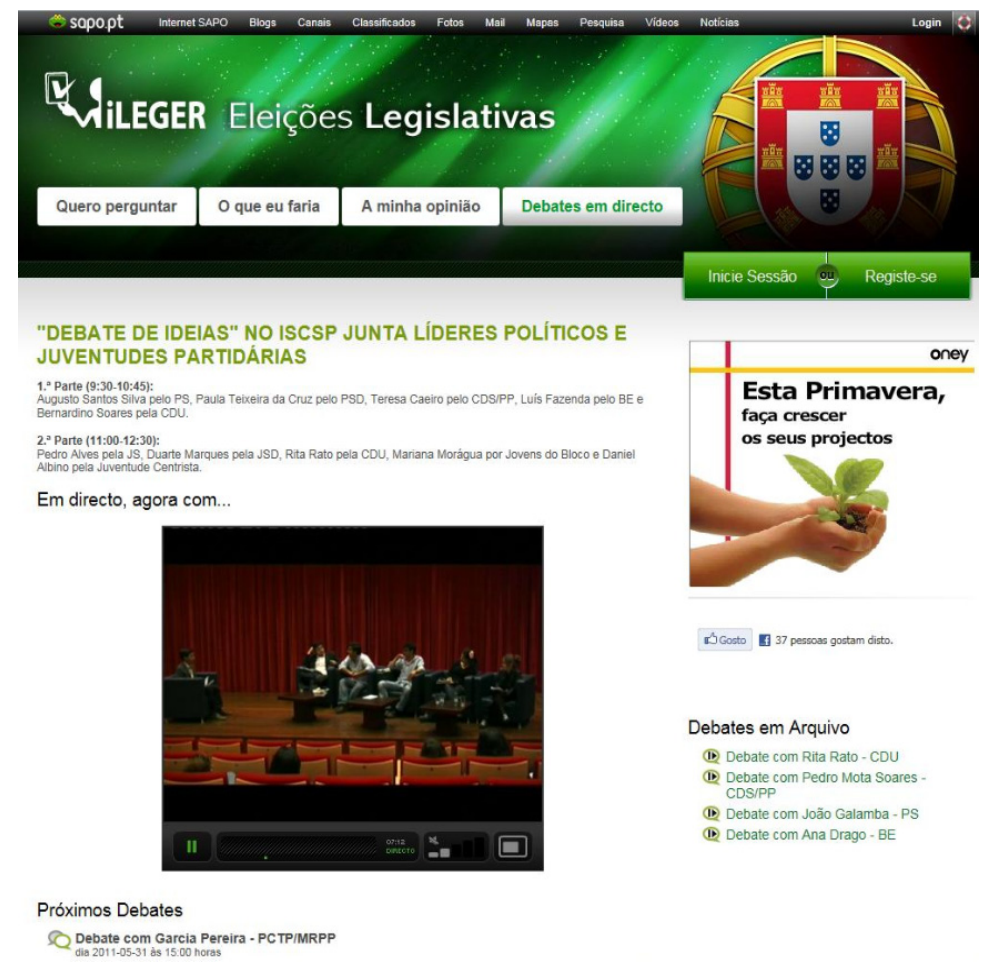

Figura 7 - Debate em direto transmitido via streaming de vídeo no iLeger nas Eleições Legislativas 2011 
Destaque-se o facto de terem aderido a esta iniciativa políticos conceituados, entre os quais líderes parlamentares e elementos que acabariam por vir a fazer parte do governo eleito como ministros.

Adicionalmente, na segunda semana foram realizados seis debates em direto, cada um com uma candidatura. Cada debate durou cerda de uma hora e meia. Ao longo dos seis debates houve 3779 entradas submetidas na forma de perguntas ou de comentários. No entanto, por restrições de tempo e de moderação, apenas 133 dessas entradas foram abordados pelas candidaturas. Para participar nos debates em direto os utilizadores não tinham que estar registados no iLeger. Para a realização dos debates em direto foi incorporado na plataforma iLeger o componente CoveritLive (www.coveritlive.com).

É importante notar que, segundo as estatísticas do Google Analytics, dos 21.486 visitantes únicos durante as duas semanas, 19.419 entraram pela primeira vez no iLeger durante os dias dos debates em direto, demonstrando o interesse dos cidadãos para participar em eventos ao vivo e de curta duração. Na Figura 8 ilustra-se a descrição geral dos visitantes do iLeger entre 20 Maio e 3 de Junho de 2011.

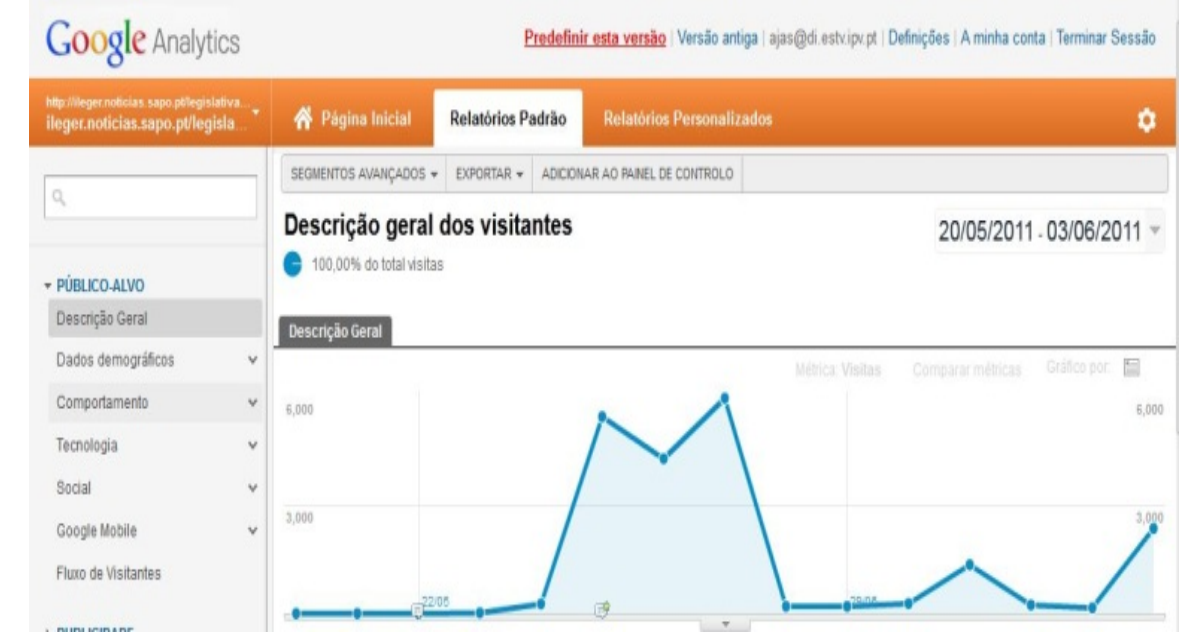

Figura 8- Descrição geral dos visitantes do iLeger entre 20 Maio e 3 de Junho de 2011

Os picos refletem os dias em que se realizaram debates em direto. Uma das possíveis razões para a grande adesão dos cidadãos nos dias dos debates em direto pode ser o facto de o nosso parceiro ter feito nesses dias maior divulgação da iniciativa na sua home page. Isto também demonstra a grande importância da divulgação das iniciativas de participação. Consideramos que os Media têm, a este nível, também um papel muito importante.

Durante as duas semanas os utilizadores registados submeteram um total de 50 sugestões, das quais 9 foram rejeitadas pelo moderador. Nesta secção do iLeger, o editor criou, em simultâneo, três iniciativas de angariação de sugestões; desafiou os cidadãos a dizer o que fariam se fossem a Chanceler Alemã Angela Merkel, o presidente do FMI (Fundo Monetário Internacional) e o presidente da União Europeia. Note-se que o editor assumiu que as personagens (tomadoras de decisão) consideradas nas três 
iniciativas de recrutamento de ideias tinham um papel preponderante na eventual ajuda externa a Portugal.

No global, houve 299 votos em perguntas, 92 votos em sugestões e 1073 votos nas 15 questões do inquérito aos cidadãos.

É também pertinente notar que, se não se contabilizarem os debates em direto, dos 290 utilizadores únicos que efetuaram login, 156 submeteram conteúdos escritos (116 perguntas e 50 sugestões) ou votaram nas perguntas, nas sugestões e nos inquéritos. Isto indica que, como ilustrado na Figura 9, participaram ativamente no iLeger aproximadamente $54 \%$ dos utilizadores que efetuaram login.

Percentagem de participação dos utilizadores que efetuaram login (sem contabilizar os debates em direto)

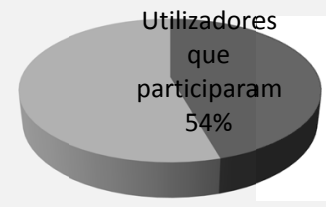

Figura 9 - Percentagem de participação dos utilizadores que efetuaram login (sem contabilizar os debates em direto)

Nestas eleições o iLeger foi usado principalmente para identificar as principais questões e sugestões dos cidadãos, bem como a sua opinião sobre os temas-chave da eleição. Através da realização dos debates em direto, foi também possível ficar com uma melhor perceção do ponto de vista dos representantes das candidaturas sobre as 10 perguntas mais votadas pelos cidadãos ao logo da primeira semana, bem como sobre outras perguntas colocadas em direto. Ao comparar os pontos de vista, os cidadãos ficam com informações adicionais sobre a posição dos candidatos acerca das principais questões, ajudando-os, eventualmente, a decidir pelo "melhor" candidato.

\section{Comentários finais}

Os partidos políticos e os candidatos a eleições têm vindo a realizar grandes investimentos (tempo, dinheiro e recursos humanos) em ferramentas de comunicação baseadas na Web, tais como as redes sociais (Facebook, Twitter, YouTube, Flickr, Myspace, entre outras), a blogosfera, e os Web sites de campanha, para transmitir as suas mensagens aos cidadãos eleitores.

Apesar de se acreditar fortemente que as ferramentas de participação baseadas na Internet, tais como as redes sociais e como a aplicação aqui apresentada, serão cada vez mais importantes em campanhas eleitorais, e que, se forem convenientemente usadas, elas têm potencial para contribuir significativamente para reverter o atual afastamento dos cidadãos dos debates eleitorais, defende-se que o foco tem que estar essencialmente na participação e nas pessoas (cidadãos e candidatos) e não tanto na tecnologia. 
Perante as experiências de utilização do iLeger nas eleições do Bastonário da Ordem dos Médicos, Presidenciais e Legislativas Portuguesas de 2011 e à luz do feedback recebido de alguns atores envolvidos nessas eleições, quando se tentou responder à questão de investigação "Como estimular os cidadãos a envolverem-se e a participar ativamente nos debates eleitorais, através de mediação digital?”, alega-se que não se alcançou uma resposta conclusiva e completa. Todavia, tal como em (Moreira, Moller \& Ladner, 2009; Stromer-Galley, 2000; Effing, Hillegersberg \& Huibers, 2011) argumenta-se que o problema da eParticipação não é apenas uma questão de tecnologia, mas também sobre a mudança para uma cultura mais aberta e de colaboração.

Espera-se que os candidatos e os representantes democráticos aproveitem as características de ubiquidade da Internet e as oportunidades da Web colaborativa, emancipando-se dos Media tradicionais, em favor da Web 2.0 e dos Media Sociais, para as suas estratégias eleitorais e de comunicação e que, cada vez mais, promovam e participem em iniciativas de participação que os aproximem mais dos cidadãos.

Ainda em relação à experiência de utilização do iLeger, considera-se que a divulgação é um fator chave para o sucesso deste tipo de iniciativas de participação. Era claramente percetível que sempre que havia divulgação na home page do nosso parceiro, aumentava consideravelmente o número de visitas no iLeger (cerca de 90\%). A parceria com um dos principais órgãos de Media de Portugal também se revelou como um fator facilitador para atrair os políticos a participar. Portanto, entende-se que os Media podem desempenhar um papel muito relevante em iniciativas de eParticipação. Note-se que eles possuem já grandes comunidades de utilizadores com alguns hábitos de participação. Por outro lado, têm também um conjunto de comentadores e analistas que podem contribuir para a qualidade das discussões. A experiência jornalística que possuem pode também contribuir para uma melhor dinamização da plataforma e para garantir a qualidade dos conteúdos editoriais. É, no entanto, muito importante que tudo seja feito com absoluta neutralidade política. Outro contributo importante resultante das nossas experiências diz respeito à gestão editorial deste tipo de aplicações. Os utilizadores habituais da Internet gostam de novidade constante. Assim, entende-se que os cidadãos (e os políticos) devem ser convidados a participar em eventos de curta duração e sobre temas da atualidade. Considera-se que os Media estão numa posição privilegiada para desempenhar o papel de curador de informação (Rosembaum, 2011) de plataformas de eParticipação.

Como resultado da experiência obtida, surgem diversas possibilidades de exploração e aprofundamento dos dados obtidos. Em particular, torna-se pertinente colocar a questão para futuro trabalho: Qual o impacto dos mecanismos de mediação digital na participação?

\section{Referências}

Abgeordneten, http://www.abgeordnetenwatch.de/ (acedido em 20 de Maio, 2010)

Afonso de Sousa, A., \& Borges Gouveia, L. (2011). Governmeter: a Web Application for Monitoring Governmental Activity. Proceedings of 6th Iberian Conference on Information Systems and Technologies - CISTI2011. Chaves, Portugal. 
Aggio, C., Marques, J., \& Sampaio, R. (2011). Campanhas Online, Participação Política e Esfera Pública: O Caso do Plano de Governo Colaborativo nas Eleições Brasileiras de 2010. Public Sphere Reconsidered -Theories and Practices, LabCom Books, pp. 3-21

Bimber, B. \& Davis, R. (2003). Campaigning Online: The Internet in U.S. Elections. Oxford University Press

CNN ElectionCenter2008. (2008). http://edition.cnn.com/ELECTION/2008/issues/ (acedido em 6 de Maio, 2010)

Effing, R., Hillegersberg, J.V., \& Huibers, T. (2011). Social Media and Political Participation: Are Facebook, Twitter and YouTube Democratizing Our Political Systems?, E. Tambouris, A. Macintosh, and H. de Bruijn (Eds.): ePart 2011, LNCS 6847, pp. 25-35

Greengard, S. (2009). The First Internet President. Communications of the ACM, 52(2), pp.16--18

Kes-Erkul, A. \& Erdem-Erkul, R. (2009). Web 2.0 in the Process of e-participation: The Case of Organizing for America and the Obama Administration. National Center for Digital Government, Working paper No. 09-001

Moreira, A.M., Moller, M., Gerhardt, G., \& Ladner, A. (2009). E-Society and EDemocracy, eGovernment Symposium, Berne, Switzerland

Rosembaum, S. (2011). Curation Nation: How to Win in a World Where Consumers are Creators. McGraw-Hill; 1st edition

Sanford, C., \& Rose, J. (2007). Characterizing eParticipation. International Journal of Information Management, vol. 27, pp. 406-421.

SmartVote (2011). http://www.smartvote.ch/ (acedido em 15 de Março, 2011)

Stromer-Galley, J. (2000). On-Line Interaction and Why Candidates Avoid It. Journal of Communication, 50(4) pp. 111-132

Talbot, D. (2008). How Obama Really Did It: The social-networking strategy that took an obscure senator to the doors of the White House. Technology Review, 9/10 